\title{
Microevolution within ST11 group Clostridioides difficile isolates through mobile genetic elements based on complete genome sequencing
}

\author{
Yuan $\mathrm{Wu}^{1,2^{*}}$, Lin Yang ${ }^{3}$, Wen-Ge Li ${ }^{1}$, Wen Zhu Zhang ${ }^{1}$, Zheng Jie Liu ${ }^{1}$ and Jin-Xing Lu ${ }^{1,2^{*}}$
}

\begin{abstract}
Background: Clade 5 Clostridioides difficile diverges significantly from the other clades and is therefore, attracting increasing attention due its great heterogeneity. In this study, we used third-generation sequencing techniques to sequence the complete whole genomes of three ST11 C. difficile isolates, RT078 and another two new ribotypes (RTs), obtained from three independent hospitalized elderly patients undergoing antibiotics treatment. Mobile genetic elements (MGEs), antibiotic-resistance, drug resistance genes, and virulent-related genes were analyzed and compared within these three isolates.
\end{abstract}

Results: Isolates 10,010 and 12,038 carried a distinct deletion in tcdA compared with isolate 21,062. Furthermore, all three isolates had identical deletions and point-mutations in $t c d C$, which was once thought to be a unique characteristic of RT078. Isolate 21,062 (RT078) had a unique plasmid, different numbers of transposons and genetic organization, and harboring special CRISPR spacers. All three isolates retained high-level sensitivity to 11 drugs and isolate 21,062 (RT078) carried distinct drug-resistance genes and loss of numerous flagellum-related genes.

Conclusions: We concluded that capillary electrophoresis based PCR-ribotyping is important for confirming RT078. Furthermore, RT078 isolates displayed specific MGEs, indicating an independent evolutionary process. In the further study, we could testify these findings with more RT078 isolates of divergent origins.

Keywords: Clostridioides difficile, tcdC deletion, Mobile genetic elements, Complete whole genome sequencing, CRISPR spacers, Capillary electrophoresis-based PCR-ribotyping

\section{Background}

Clostridioides difficile has emerged as the leading cause of antimicrobial and health care-associated diarrhea in humans [1]. C. difficile is widespread in the environment and the gastrointestinal tracts of humans and animals $[2,3]$. The population structure of $C$. difficile consists mainly of 6 clades, clade1-5 and clade C-I [4]. Hypervirulent PCR-ribotype 027 from clade 2 has caused outbreaks and transmission around the world [5]. RT078, contained in clade 5 , is important in animal infections, and its incidence in cases of symptomatic human infection is

\footnotetext{
* Correspondence: wuyuan@icdc.cn; lujinxing@icdc.cn

${ }^{1}$ State Key Laboratory of Infectious Disease Prevention and Control, National Institute for Communicable Disease Control and Prevention, Chinese Center for Disease Control and Prevention, Beijing, China

Full list of author information is available at the end of the article
}

increasing $[6,7]$. There are at least 3 STs in clade 5 , and 10 RTs $(033,045,066,078,126,127,193,237,280$, and 281) for ST11 [8, 9]. The high proportion of mobile genetic elements (MGEs) (about 11\% in strain 630) contributes to the remarkable dynamic and mosaic genome of $C$. difficile [10]. Transposable and conjugative elements, plasmids, bacteriophages, and clustered regularly interspersed short palindromic repeat (CRISPR) elements are considered as the main MGEs and play important roles in horizontal gene transfer (HGT) of C. difficile [11-13].

In our previous study, we characterized three ST11 $C$. difficile isolates from elderly hospitalized patients with distinct RTs were reported [9]. Here, we continued our in-depth exploration of the genetic features and genomic differences among those three closely related isolates

(c) The Author(s). 2019 Open Access This article is distributed under the terms of the Creative Commons Attribution 4.0 International License (http://creativecommons.org/licenses/by/4.0/), which permits unrestricted use, distribution, and reproduction in any medium, provided you give appropriate credit to the original author(s) and the source, provide a link to the Creative Commons license, and indicate if changes were made. The Creative Commons Public Domain Dedication waiver (http://creativecommons.org/publicdomain/zero/1.0/) applies to the data made available in this article, unless otherwise stated. 
based on complete whole genome sequencing to provide a better understanding of the microevolution within the ST11 group of $C$. difficile, and help accurately identification of hypervirulent RT078.

\section{Results and discussion}

\section{Genomic features of the three $C$. difficile isolates}

The three isolates 10,010 (new RT), 12,038 (new RT), and 21,062 (RT 078) used in this study have same MLST type (ST11) and toxin gene profile $\left(t c d A^{+} t c d B^{+} c d t A / B^{+}\right)$, however, in our previous study, we identified differences in PCR-ribotyping by capillary electrophoresis using the QIAXcel and ABT3730 systems [9]. The genome sizes of the three $C$. difficile isolates ranged from $3.99-4.07 \mathrm{Mb}$, of which isolate 21,063 had the fewest coding sequences (Table 1) (Additional file 1). The number and types of non-coding RNAs (ncRNA) and tandem repeats (TRs) are also summarized in Table 1. Schematic diagrams of the three complete chromosome genomes and two plasmid genomes are displayed in (Fig. 1). Isolates 12,038 and 21,062 carried one plasmid each (Fig. 1). Plasmid 12,038 had only 3 annotated genes, while plasmid 21,062 contained 69 genes, most of which encoded proteins involved in cell metabolism and transcriptional regulation. Furthermore, only one antibiotic-resistance gene, $r р о B$ (associated with rifampicin resistance), was harbored on plasmid 21,062 (Fig. 1). For many bacteria, plasmids play an important role in drug resistance and are responsible for resistance transmission. However, in C. difficile, drug resistance genes are mainly carried on transposons not plasmid [12]. The first whole genome sequence of $C$. difficile was obtained for strain 630 and consists of a circular chromosome of $4.4 \mathrm{Mb}$ and a plasmid, pCD630 of 7881 bp $[10,14]$. Compared with strain 630 , the three $C$. difficile isolates investigated in this study contained a smaller size of chromosomes with fewer coding sequences (Table 1 and Fig. 1). In addition, two plasmids identified in this study were larger than pCD630 (Fig. 1), which harbors 11 coding sequences (CDSs) with no obvious function. Importantly, CDSs carried by plasmid 21, 062 and 12,038 were annotated as functional genes involved in many metabolic processes in C. difficile isolates, including the antibiotic resistance (Fig. 1).
The genetic features of PaLoc and CdtLoc regions 3 ST11 C. difficile isolates

All the three $C$. difficile isolates, which were $t c d A^{+} t c d B^{+} c d t A$ / $B^{+}$positive, contained intact PaLoc and CdtLoc regions (Fig. 2). The PaLoc and CdtLoc regions among these isolates were almost identical (Fig. 2). Specifically, the location and length of deletions and insertions (indels) were the same, except the $661 \mathrm{bp}$ deletion within $t c d A$, which was present only in isolate 10,010 and 12,038 (Fig. 2a). Compared with the other two isolates, isolate 21,062 contained a slightly greater number of single nucleotide polymorphism (SNPs), both synonymous and non-synonymous, within $t c d A$ (Fig. 2a). However, the potential of this specific $661 \mathrm{bp}$ deletion within $t c d A$ as a unique marker of RT078 C. difficile remains to be confirmed in further studies of with more ST11 isolates. For CdtLoc region, the most significant characteristic was the intact $c d t A$ and $c d t B$ genes (with length of $6.2 \mathrm{~kb}$ ) harbored by the three isolates (Fig. 2b), compared with truncated $c d t A$ and $c d t B$ gene (with length of $4.2 \mathrm{~kb}$ ) in CD630 [10]. Moreover, the $165 \mathrm{bp}$ deletion within the CD2601 coding region was found only in isolate 12,038 (Fig. 2b). The SNPs in $c d t R, c d t A, c d t B$, trpS, and intergenic regions in the three isolates were totally identical (Fig. 2b).

Importantly, a point mutation at position 184 and $\triangle 39$-bp deletion within $t c d C$ has been reported as a specific feature of RT078 [15]. However, the $\Delta 39$-bp deletion was detected in all three ST $11 \mathrm{C}$. difficile isolates (Fig. 2a and Fig. 3). To explore the point mutations within $t c d C$ in detail, the full length $t c d C$ sequences from the three isolates were compared, which indicated that the point mutations were totally identical, including that at position 184 site leading to deletion of the amino acid Gln (Fig. 3). There were a total of 12 point mutations within $t c d C$, in which mutations at point positions 21, 54, 117,183-4, 430, 516, and 558 caused amino acid changes (Fig. 3). This result indicates that ST type together with toxin profile and deletions/mutation in $t c d C$ cannot be used to confirm the hypervirulent RT078 $C$. difficile isolates. Identification of RT078 requires confirmation by PCR capillary electrophoresis, which is consistent with the findings of our previous study [9]. The $t c d C$ gene encodes a negative regulator protein of toxins

Table 1 General feature of three ST 11 C. difficile isolates

\begin{tabular}{|c|c|c|c|c|c|c|c|c|c|c|c|c|c|}
\hline Isolate & RT & $\begin{array}{l}\text { Toxin } \\
\text { gene }\end{array}$ & Origin & Age & $\begin{array}{l}\text { Size } \\
\text { Mp }\end{array}$ & CDS & tRNA & sRNA & TRF & $\begin{array}{l}\text { Minisatellite } \\
\text { DNA }\end{array}$ & Plasmids & Transposons & $\overline{\text { Prophage }}$ \\
\hline $\begin{array}{l}10, \\
010\end{array}$ & new & $\begin{array}{l}\mathrm{A}+\mathrm{B}+ \\
\mathrm{CDT}+\end{array}$ & human & 89 & 4.05 & 3624 & 89 & 52 & 481 & 367 & 0 & $\begin{array}{l}\text { CTn1, CTn2, CTn4, CTn5, CTn6*, CTn7, } \\
\text { Tn916, Tn6103,Tn5398* }\end{array}$ & 3 \\
\hline $\begin{array}{l}12 \\
038\end{array}$ & new & $\begin{array}{l}\mathrm{A}+\mathrm{B}+ \\
\mathrm{CDT}+\end{array}$ & human & 89 & 4.07 & 3633 & 109 & 52 & 481 & 367 & 1 & $\begin{array}{l}\text { CTn1, CTn2, CTn4, CTn5, CTn6*, CTn7, } \\
\text { Tn6103, Tn5398* }\end{array}$ & 3 \\
\hline $\begin{array}{l}21 \\
062\end{array}$ & 078 & $\begin{array}{l}\mathrm{A}+\mathrm{B}+ \\
\mathrm{CDT}+\end{array}$ & human & 92 & 3.99 & 3565 & 89 & 59 & 468 & 355 & 1 & $\begin{array}{l}\text { CTn1, CTn4, CTn6*, CTn7, Tn5397, } \\
\text { Tn5398*, Tn4453a }\end{array}$ & 2 \\
\hline
\end{tabular}



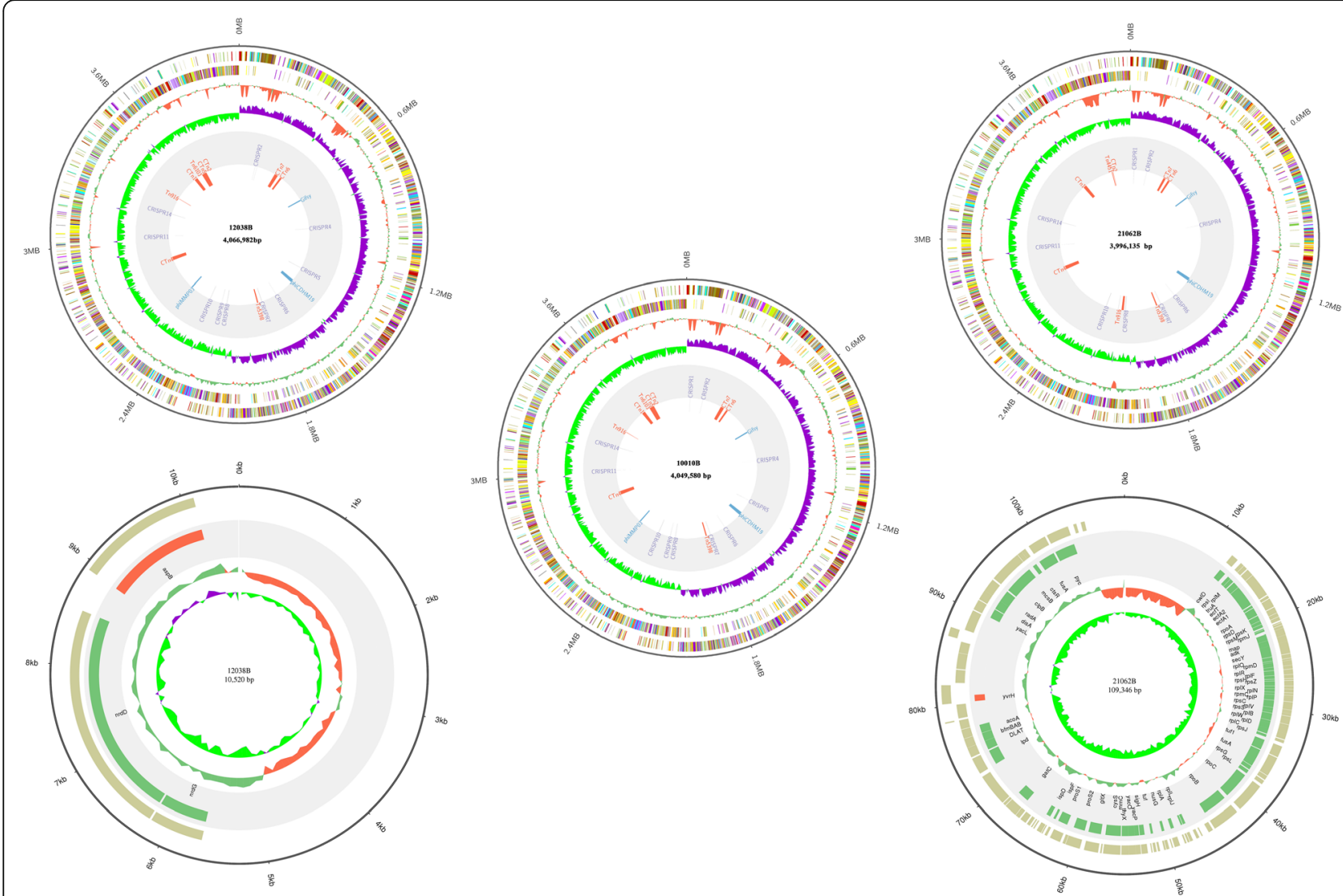

Fig. 1 Schematic diagram of the complete whole chromosome and plasmid genomes of the three ST 11 Clostridium difficile isolates. For the chromosome genomes, the circles (from the out layer inward) represent the genomes, the annotated COG genes on the positive strand, the annotated COG genes on the negative strand, GC content, GC skew, mobile genetic elements (red: the transposons; purple: the CRISPR; green: the prophages), and the name and genome size of the isolates, respectively. For the plasmid genomes, the circles (from the outer layer inward) refer to GC skew, GC content, reverse strand genes, forward strand genes, all annotated genes and genome size

$A$ and $B$ in $C$. difficile $[6,16]$. It is known that $t c d C$ deletions lead to higher amounts of toxins $\mathrm{A}$ and $\mathrm{B}$ in RT027 [17]; however, the effect of the $\triangle 39$-bp deletion on the translation and expression of toxins in ST11 remains to be clarified.

\section{Analysis of the transposon and conjugative transposon in the three $C$. difficile isolates}

A total of 11 types of transposons and conjugative transposons were identified in the three isolates (Table 2). Seven transposons reported in CD630 were all identified in the three isolates, although CTn 2 and CTn 5 were absent in isolate 21,062, and $\operatorname{Tn} 5397$ was absent in isolate 10,010 and 12,038 (Table 1).

CTn1 has 32 ORFs in CD630, including a tyrosine integrase. CTn1-like elements in the three isolates were exactly the same as that in CTn1 of CD630 but with fewer ORFs, the deletions of which were mainly existed in conjugative and accessary regions (Table 2 and Fig. 4). In addition, a transposase was found in these CTn1-like elements (Fig. 4). CTn2-like elements were detected only in isolates 10,010 and 12,038, but unlike the CT2 containing a serine recombinase, there was no transposase (Table 2 and Fig. 4). Only one open reading frame (ORF) encoding DNA helicase was retained in isolate 21, 062 (Fig. 4). Tn5397, previously known as CTn3, was the first Tn916-like element to be extensively characterized in $C$. difficile [13]. This $21 \mathrm{~kb}$ element encodes tetracycline resistance via tet $(\mathrm{M})$ and is highly related to Tn916 across its length apart from the ends $[4,18]$, where two genes, xisTn and intTn, in Tn916 are replaced by gene tndX in Tn5397. In this study, a Tn5397-like element found only in isolate 21,062 was devoid of $\operatorname{tndX}$ and a group II intron in orf14, while tet(M) was retained (Table 2 and Fig. 5). Due to the difference in gene composition between $\operatorname{Tn} 916$ and Tn5397, Tn916 has the ability to insert into multiple sites in the genome although it has a preferred consensus site, while Tn5397 inserts into DNA predicted to encode a domain initially termed Fic (filamentation processes induced by cAMP) [19]. Bi-directional horizontal gene transfer of Tn5397 between $C$. difficile strains and E. faecalis $\mathrm{JH} 2-2$, has 


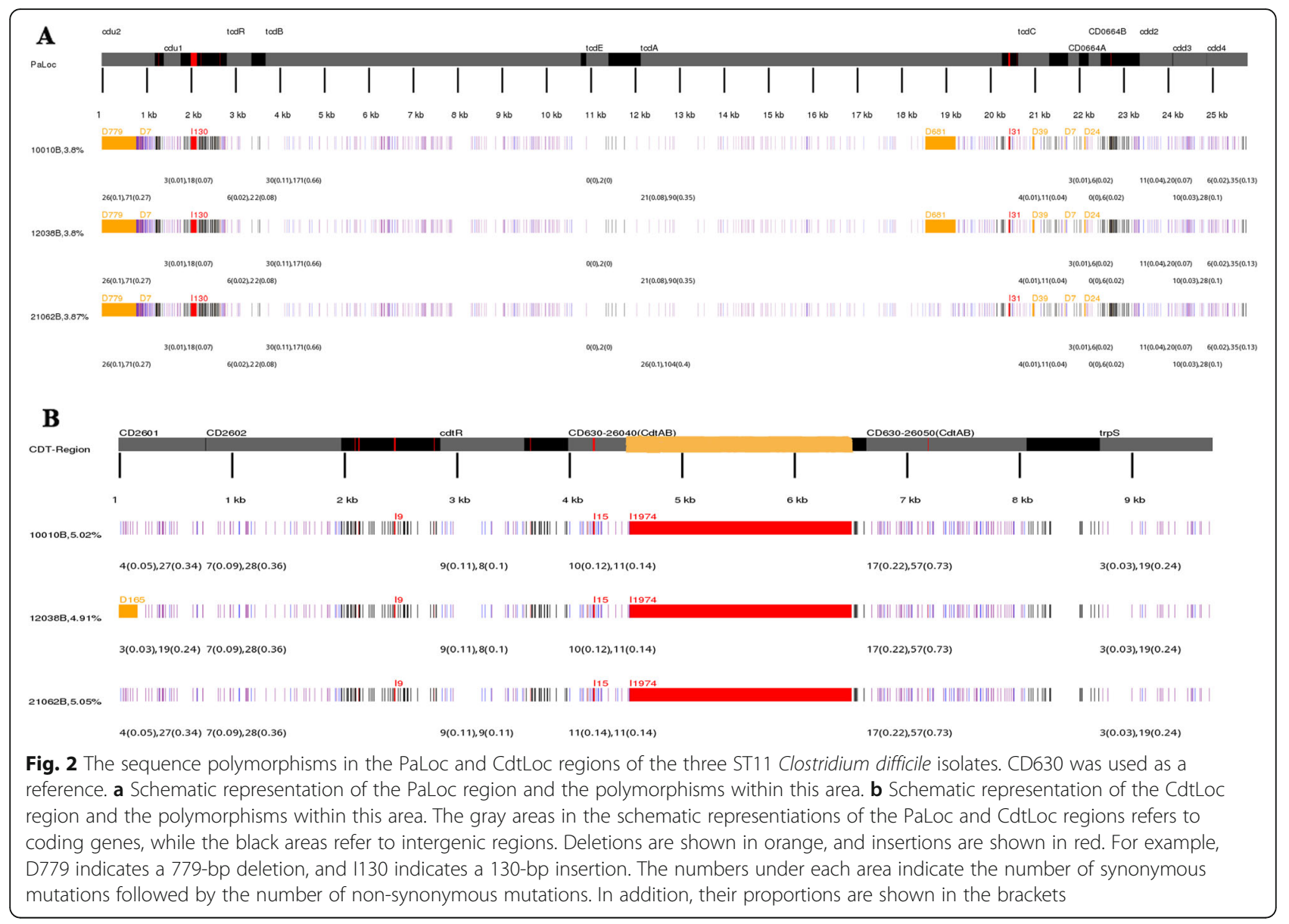

been recently demonstrated [20]. However, the ability of the Tn5397-like element identified in this study to transfer between $C$. difficile, and other isolates, requires further investigation. CTn4-like elements with identical gene structure and order were detected in all three isolates (Fig. 4), and contained xisTn and $i n t T n$ as detected in CTn4 of CD630 (Table 2). CTn5 is a Tn1549-like element and undergoes excision from the host genome at a transfer frequency of $2.8 \times 10^{-5}[18,21]$. In this study, CTn5-like elements with almost identical gene composition were only found in isolates 10,020 and 12, 038 (Fig. 4). CTn6 harbors a tyrosine integrase gene but without the excision ability. The novel elements identified in the three ST11 isolates in this study carried only two homologous genes (CD3337, encoding a membrane protein, and CD3343, encoding an AraC family transcriptional regulator) with CTn6 (Fig. 5). Although there were no transposase genes, the novel element contained several genes encoding an $\mathrm{ABC}$ transporter in. The significance of $\mathrm{CTn} 7$ is the presence of a large serine recombinase. CTn7-like elements with completely identical gene composition and order were identified in isolates 10,010 and 12,038 (Fig. 4). Interestingly, the CTn7-like element in isolate 21,062 was devoid of nearly one-third of the ORFs compared with the other two isolates, including the transposase homologous with CTn7, and seven flagella encoding genes (Fig. 4), although the impact of this on the flagella production and movement of isolate 21,062 (RT078) compared with isolates 10,010 and 12,038 remains to be determined. Tn916 is one of the two largest families of conjugative transposons in $C$. difficile, carrying 24 potential ORFs, including tet(M), xisTn (an excisionase) and intTh (a tyrosine integrase), responsible for tetracycline resistance, excision, circularization and integration of the element [22]. In this study, a Tn916-like element retaining the tet $(\mathrm{M})$ and transposase was identified only in isolate 21,062 , while in isolate 10 , 010 and 12,038, there was only one ORF encoding an integrase (Fig. 5). Tn5398 is a particular element in C. difficile, having no transposase, no circular form, but having an oriT site and two copies of the ermB genes [13]. Tn5398 had been reported to transfer between $C$. difficile strains and from C. difficile to Staphylococcus aureus and Bacillus subtilis [23]. All three isolates in this study carried a Tn5398-like element was found to be absent with ermB genes and other potential genes (Fig. 5). The very large Tn6103 (84.9 kb) was first recognized in strain R20291 (RT027) [12]. Although this element shows highly 


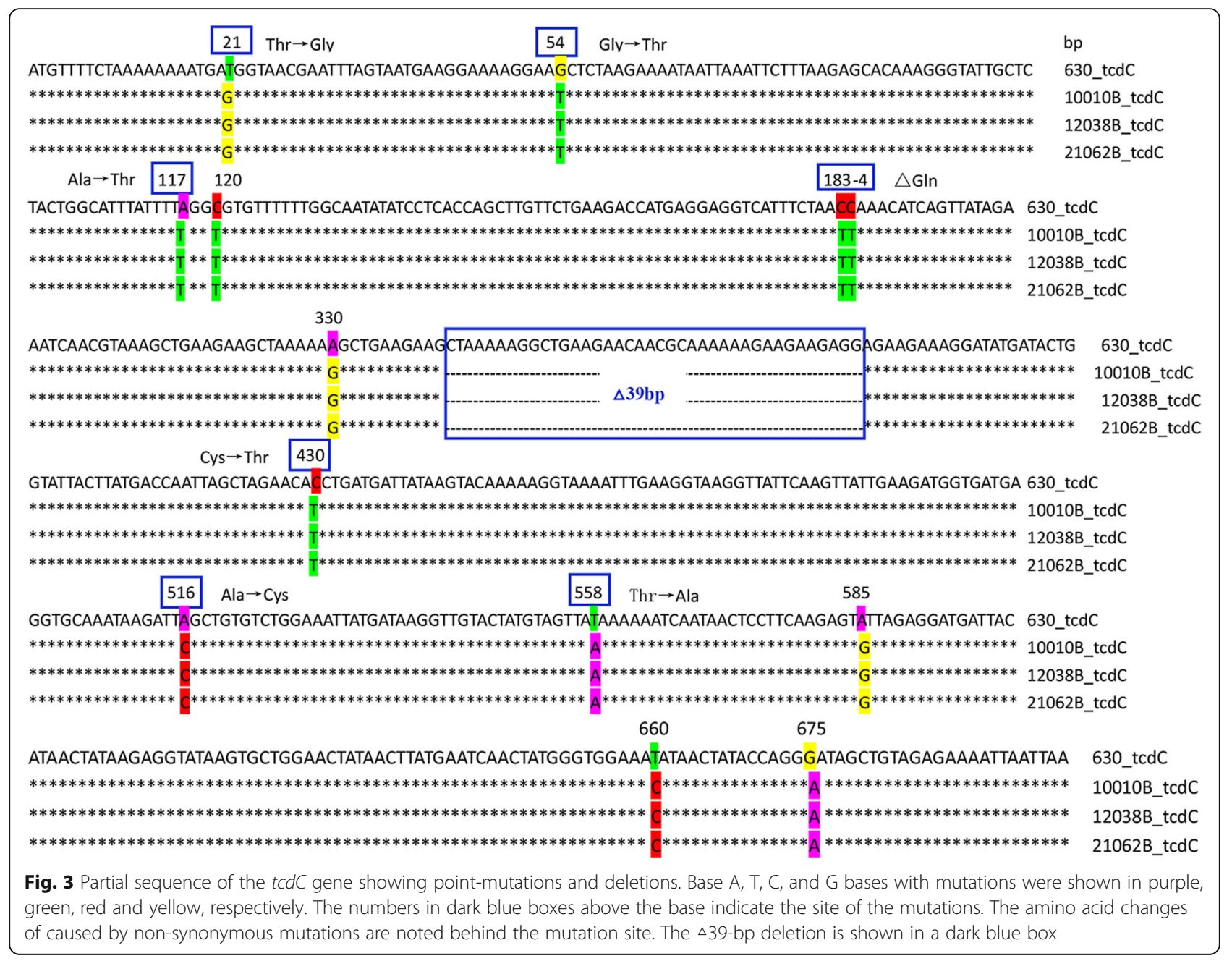

similarity with CTn5, there are three insertions of putative mobilizable transposons, designated Tn6104, Tn6105 (both $15 \mathrm{~kb}$ and inserted into CD1743), and Tn6105 (10 $\mathrm{kb}$ inserted into CD1776b) [13]. A Tn6103-like element was found in isolate 10,010 and 12,038, losing the whole Tn6104 and almost the entirely Tn6105 (Fig. 4). $\operatorname{Tn} 4453 a / b$ is the smallest element with only 7 ORFs in strain W1, of which the representative feature is carrying the gene catD [24]. A Tn4453a/b-like element was identified only in isolate 21,062 but without the gene catD gene, which was replaced by aac (21062BGL003409) (Fig. 5). Only one ORF encoding a helicase was found in isolate 10,010 and 12,018 (Fig. 5). It is known that aac encodes a bi-functional AME, accounting for more than $90 \%$ of high level gentamicin resistance (HLGR) in E. faecalis and E. faecium [25]. In our previous study of clade 4 C. difficile isolates, the same replacement in $\operatorname{Tn} 4453 a / b$ was also identified in some ST81/RT017 isolates (manuscript under review). However, the situation that promotes this replacement and whether this newly reported Tn $4453 a / b$ is transferred between intestinal bacteria as a complete element remain to be determined.

Transposons play an important role in the transfer of drug-resistance gene within $C$. difficile isolates, and between $C$. difficile and other bacteria, and in the genome re-construction, resulting in distinct phenotype in $C$. difficile. In this study, the RT078/ST11 isolate contained totally different transposon elements compared with the ST11 non-RT078 isolates. This indicates that these closely related isolates underwent distinct evolutionary processes, with RT078 derived from specific division pathway.

\section{CRISPRs reveal potential evolution pathways of the 3 ST11 C. difficile isolates}

In searches of these 3 isolates, 13, 14, and 12 CRISPR arrays were identified in isolates 10,010, 12,038, and 21, 062, respectively. Among the 14 arrays in 12,038, one was located in a plasmid. Based on subsequent comparison and classification of those arrays, a total of 14 types 
Table 2 Transposons and conjugative transposons analyzed in this study

\begin{tabular}{|c|c|c|c|c|c|c|c|c|c|c|c|c|c|}
\hline \multirow[t]{2}{*}{ Transposons } & \multirow{2}{*}{$\begin{array}{l}\text { Referenced } \\
\text { Isolates }\end{array}$} & \multicolumn{5}{|c|}{ Reference } & \multicolumn{2}{|c|}{ Isolate 10,010} & \multicolumn{2}{|c|}{ Isolate 12,038} & \multicolumn{2}{|c|}{ Isolate 21,062} & \multirow{2}{*}{$\begin{array}{l}\text { Common } \\
\text { ORF }^{\mathrm{a}}\end{array}$} \\
\hline & & ORF & $\begin{array}{l}\text { Size } \\
(\mathrm{kb})\end{array}$ & Strat-end & GC\% & Specific gene & ORF & enzymes & ORF & enzymes & ORF & enzymes & \\
\hline CTn1 & CD630 & 32 & 28.9 & $\begin{array}{l}\text { CD0355- } \\
0386\end{array}$ & 38.6 & $\begin{array}{l}\text { Xis, tyro- } \\
\text { integrase }\end{array}$ & 24 & transposase & 24 & transposase & 24 & transposase & 10 \\
\hline CTn2 & CD630 & 36 & 42.2 & $\begin{array}{l}\text { CD0408- } \\
0436\end{array}$ & 35.1 & seri-rebombinase & 21 & N & 21 & N & 1 & $\begin{array}{l}\text { DNA } \\
\text { helicase }\end{array}$ & 13 \\
\hline Tn5397 & CD630 & 19 & 20.7 & $\begin{array}{l}\text { CD0496- } \\
0511\end{array}$ & 38.3 & $\begin{array}{l}\text { tndX, tetM, } \\
\text { group II intron }\end{array}$ & $\mathrm{N}$ & N & $\mathrm{N}$ & $\mathrm{N}$ & 11 & tetM & 9 \\
\hline CTn4 & CD630 & 28 & 30.5 & $\begin{array}{l}\text { CD1091- } \\
1118\end{array}$ & 46.6 & $\begin{array}{l}\text { Xis, int, } \\
\text { transposase }\end{array}$ & 28 & $\begin{array}{l}\text { Xis, int, } \\
\text { transposase }\end{array}$ & 28 & $\begin{array}{l}\text { Xis, int, } \\
\text { transposase }\end{array}$ & 28 & $\begin{array}{l}\text { Xis, int, } \\
\text { transposase }\end{array}$ & 13 \\
\hline CTn5 & CD630 & 40 & 45.6 & $\begin{array}{l}\text { CD1845- } \\
1878\end{array}$ & 32.7 & & 35 & & 36 & & $\mathrm{~N}$ & $\mathrm{~N}$ & 25 \\
\hline $\begin{array}{l}\text { CTn6 } \\
\text { (novel) }\end{array}$ & CD630 & 26 & 21.3 & $\begin{array}{l}\text { CD3326- } \\
3348\end{array}$ & 42.8 & tyrointegrase & 11 & N & 12 & $\mathrm{~N}$ & 12 & $\mathrm{~N}$ & 2 \\
\hline CTn7 & CD630 & 30 & 29.2 & $\begin{array}{l}\text { CD3370- } \\
3392\end{array}$ & 40.9 & seri-rebombinase & 31 & seri & 31 & seri & 19 & N & 5 \\
\hline Tn6103 & R20291 & & 84.9 & $\begin{array}{l}1740- \\
1809\end{array}$ & 41.2 & rebombinase & & & & & & & \\
\hline Tn916 & & 24 & 18 & & & tetM, Xis, int & 1 & integrase & 1 & integrase & 13 & $\begin{array}{l}\text { tetM, } \\
\text { transposase }\end{array}$ & 11 \\
\hline Tn5398 & CD630 & 17 & 9.6 & $\begin{array}{l}\text { CD2001- } \\
\text { 2010b }\end{array}$ & 35.4 & ermB & 7 & N & 7 & N & 7 & N & 5 \\
\hline Tn4453a/b & W1 & 7 & 6.3 & $\begin{array}{l}\text { Tnpx- } \\
\text { tnpw }\end{array}$ & & catD & 1 & helicase & 1 & helicase & 10 & $\mathrm{~N}$ & 3 \\
\hline
\end{tabular}

${ }^{a}$ refers to ORFs found in the three isolates and reference CD630

of CRISPR arrays were determined; these were designated CRISPR1-14 (Table 3). CRISPRs 1, 2, 3, 6, and 13 contained only one spacer that is identical within the isolates carrying them (Table 3). However, the distribution of CRISPRs $1,2,3,6$, and 13 among the three isolates was distinct, for example, CRISPR1 was absent from isolate 12,038, which was the only strain harboring CRISPR3 (Table 3). The remaining CRISPRs are shown as two groups with various numbers of spacers in Figs. 6 and 7. Identical CRISPRs with more than one spacer were detected in isolates 10,010 and 12,038 (Table 3, Figs. 6 and 7). Importantly, CRISPRs identified in isolate 21,062 (RT078) were distinct from those in the other two isolates (Figs. 6 and 7). Specifically, CRISPRs 3 and 5 were absent, and furthermore, in CRISPRs 7-10 and 14, there was great variation in the number and length of spacers, with numerous deletions and insertions of specific spacers (Figs. 6 and 7). In addition, CRISPRs 2, 4, 6, 11, 12, and 13 contained identical spacers in the three ST11 isolates, but with different RTs (Table 3, Fig. 7).

It is noteworthy that, compared with isolates 10,010 and 12,038 , CRISPR 7 in isolate 21,062 retained the 14 identical spacers on the right side, while 8 spacers on the left were absent (Fig. 6). Spacers in CRISPR arrays are derived from foreign genetic elements in a linear, time-resolved manner [26]. These unique DNA sequences are known to maintain memory against exogenous infection, and the newly obtained DNA (spacer) is located on the $5^{\prime}$ end of the CRISPR arrays $[27,28]$. This phenomenon observed in CRISPR 7 in this study indicates that isolate 21,062 has undergone similar infection events to those of the other two isolates in the past, but have diverged in recent evolution, they became divided. In a previous study of the CRISPR-Cas system in C. difficile, the CRISPR arrays reached 8.5 arrays/genome [29], however, this number was markedly enriched at 12.5 arrays/genome in our previous study of clade 4 strains (manuscript under reviewed). In the three clade 5 ST11 $C$. difficile isolates in this study, the average number of arrays/genome was 13 . CRISPR-Cas genotyping is associated with outbreak tracking, important phenotypes (antibiotic-resistance cassettes), and prophages. Differences among the CRISPR spacers in the closely related isolates in this study reflect the role of CRISPR-Cas systems in controlling the uptake and dissemination of particular genes and operons involved in bacterial adaption and pathogenesis as well as the specific evolution and genotyping of closely related isolates [30]. In this study, large numbers of spacer deletions and acquisitions were identified in the three ST11 group isolates, demonstrating that dynamic changes have occurred in the CRISPR array content. Furthermore, although the three isolates all belongs to ST11 group, unique genetic changes were identified in the spacers in RT 078, suggesting the possibility of distinct interactions with foreign DNA 


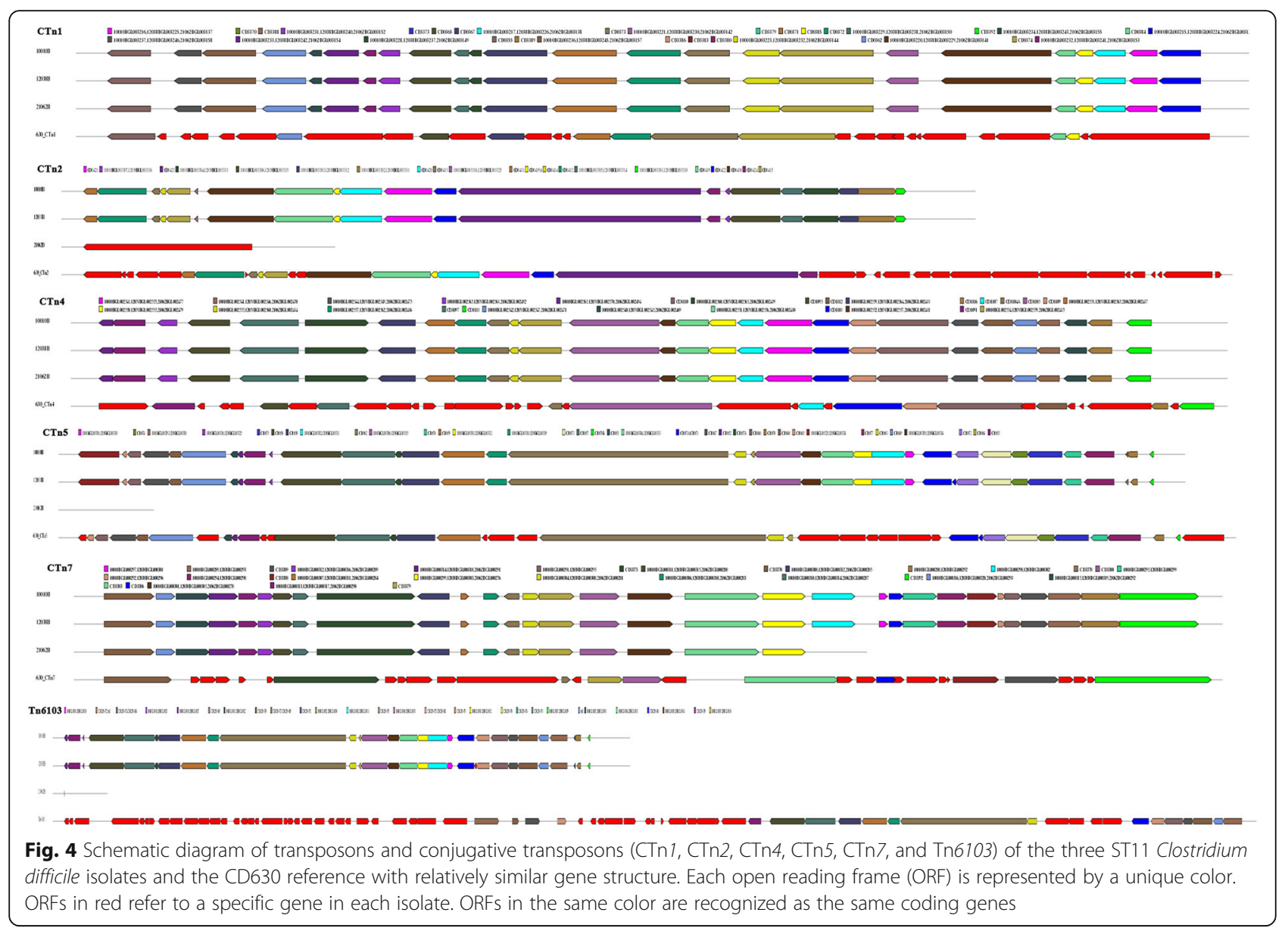

elements within the three isolates. Similarly, in a previous study, stain M120 (RT 078) was shown to possesses the largest number of unique spacers, and also to have hits to a Clostridium plasmid [31].

\section{Antimicrobial susceptibility tests and related drug- resistance genes carried by the three ST11 C. difficile isolates}

Three of the isolates demonstrated high sensitivity to 11 antibiotics, except isolate 12,038 , which was resistant to CIP, and isolate 21,062 which showed intermediate susceptibility to CLI. The hypervirulent RT027 is always associated with fluoroquinolone resistance. In our previous study of clade 4 C. difficile isolates, over $90 \%$ of the isolates exhibited multi-drug resistance (MDR), and all isolates displayed resistance to CIP (manuscript under reviewed). Surprisingly, all these three isolates were from elderly hospitalized patients undergoing antibiotics treatment [9]. Although the reasons for the high level of antibiotic susceptibility observed in the three isolates in this study are unclear, it can be speculated that the prolonged duration of antibiotic usage might suppress the diversity of the gut microbiota, leading to low rates of horizontal gene transfer by mobile genetic elements, and thereby, reducing the acquisition of antibiotic resistance genes.

We explored the antibiotic-resistance and virulence related genes throughout the genomes of the three isolates by comparisons with the CARD, ARDB and VFDB databases (Fig. 8). Isolate 21,062 (RT078/ST11) displayed a unique genes composition with several genes absent or present compared with those of the other two isolates (Fig. 8). A series of genes from $f l i P$ to $f l i M$, which encode proteins related to flagellum structure, biosynthesis and motility, were absent in isolate 21,062 (Fig. 8). In addition, another series of genes predominantly related to vancomycin resistance (vanZ, vanZA, vanB, vanUG, and $\operatorname{van} X Y L$ ), were also absent in strain 21,062 (Fig. 8). However, all these three isolates displayed high sensitivity to vancomycin in E-test analysis, which indicates that these genes are not critical elements for VAN resistance, or that they contain non-functional ORFs. A vanB operon in Tn1549 responsible for VAN resistance was originally described in E. faecalis [32]. In a recent report, a vanG-like gene cluster, homologous to the cluster found in E. faecalis, was described in a number of ST11 C. 


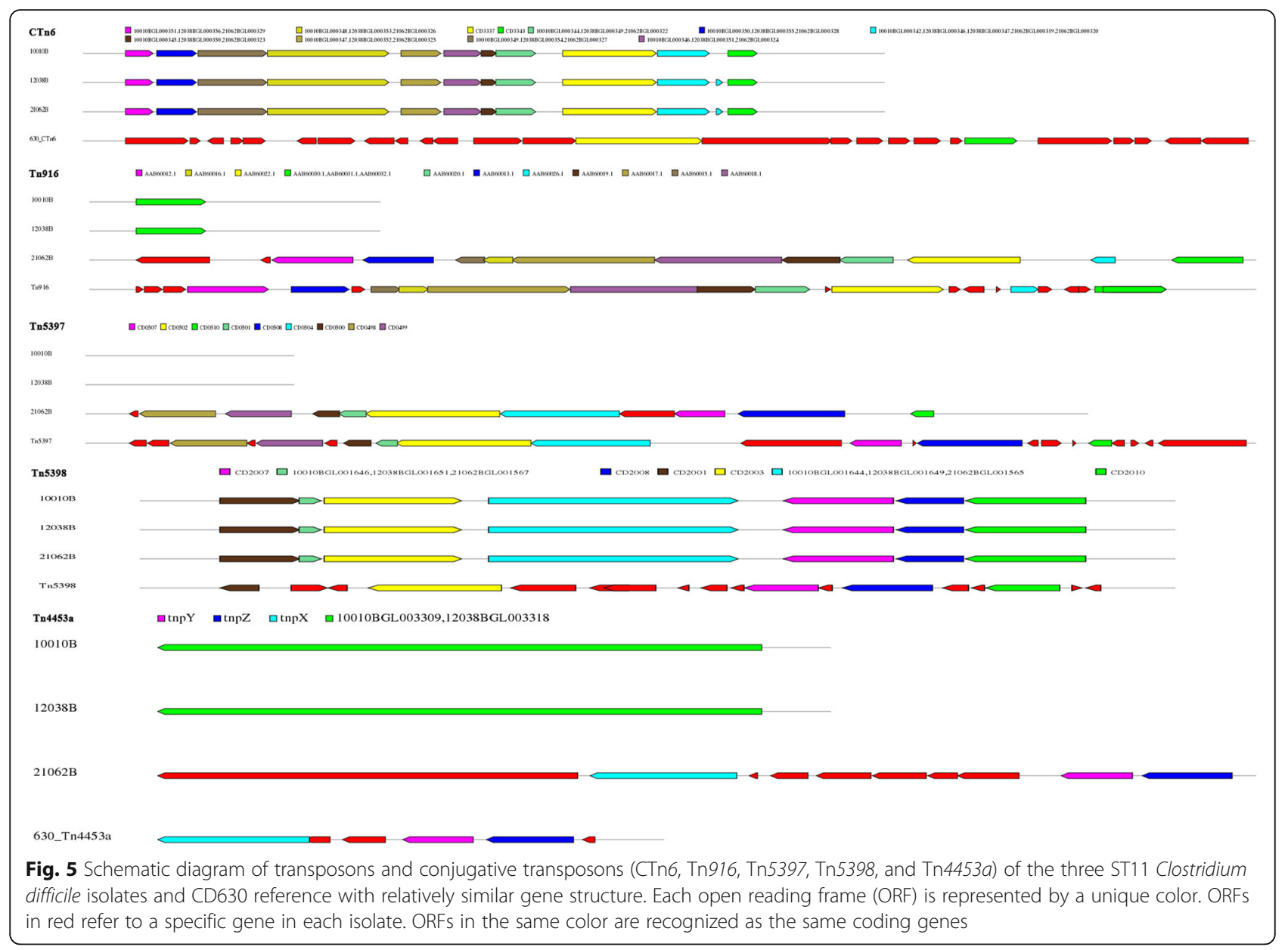

difficile isolates, and although this cluster is expressed, it is still unable to promote resistance to VAN [33]. Furthermore, strain 21,062 also carry specific genes that were absent in the other two isolates, such as tet $D$ and tet $O$ responsible for TET resistance, and aac6ie, and aac6ia responsible for resistance to aminoglycoside antibiotics. The gene compositions of isolates 10,010 and 12,038 are almost identical, with the exception of the distribution of three genes (tetD, vanXYL, and vanXYC) (Fig. 8). The effects of the loss of flagellum-related genes on the motility and invasive abilities of isolate 21,062 compared with those of the other two isolates in which the genes are present remains to be investigated.

\section{Conclusions}

This study comprehensively studied the MGEs, antibioticresistance genes, and virulent-related genes within ST11 group through the third WGS, which gave insights into the independent microevolution and genome reconstruction of ST11 C. difficile isolates. Furthermore, these genetic elements were distinct in RT078 and the other two closely related strains, which might be used as identification and classification markers for RT078. In addition, capillary electrophoresis based PCR-ribotyping is important for confirming RT078, because it carried exactly the same $t c d C$ gene with the other two ST11 isolates.

Table 3 The 14 CRISPRs identified in three isolates

\begin{tabular}{|c|c|c|c|c|c|c|c|c|c|c|c|c|c|c|}
\hline \multirow[t]{2}{*}{ Isolate } & \multicolumn{14}{|c|}{ CRISPR name } \\
\hline & 1 & 2 & 3 & 4 & 5 & 6 & 7 & 8 & 9 & 10 & 11 & 12 & 13 & 14 \\
\hline $10,010(162)$ & $\sqrt{ }(1)$ & $\sqrt{ }(1)$ & $\times(0)$ & $\sqrt{ }(8)$ & $\sqrt{ }(8)$ & $\sqrt{ }(1)$ & $\sqrt{ }(25)$ & $\sqrt{ }(29)$ & $\sqrt{ }(11)$ & $\sqrt{ }(27)$ & $\sqrt{ }(4)$ & $\sqrt{ }(3)$ & $\sqrt{ }(1)$ & $\sqrt{(43)}$ \\
\hline $12,038(162)$ & $\times(0)$ & $\sqrt{ }(1)$ & $\sqrt{ }(1)$ & $\sqrt{ }(8)$ & $\sqrt{ }(8)$ & $\sqrt{ }(1)$ & $\sqrt{ }(25)$ & $\sqrt{ }(29)$ & $\sqrt{ }(11)$ & $\sqrt{ }(27)$ & $\sqrt{ }(4)$ & $\sqrt{ }(3)$ & $\sqrt{ }(1)$ & $\sqrt{ }(43)$ \\
\hline $21,062(163)$ & $\sqrt{ }(1)$ & $\sqrt{ }(1)$ & $\times(0)$ & $\sqrt{ }(8)$ & $\times(0)$ & $\sqrt{ }(1)$ & $\Delta(17)$ & $\Delta(44)$ & $\Delta(13)$ & $\Delta(38)$ & $\sqrt{ }(4)$ & $\sqrt{ }(3)$ & $\sqrt{ }(1)$ & $\Delta(32)$ \\
\hline
\end{tabular}

$\sqrt{ }$ :The same spacers in three isolates; $\times$ : deletions of spacers; $\Delta$ : unique spacers in isolate 21,$062 ;$ numbers in brackets refer numbers of spacers 


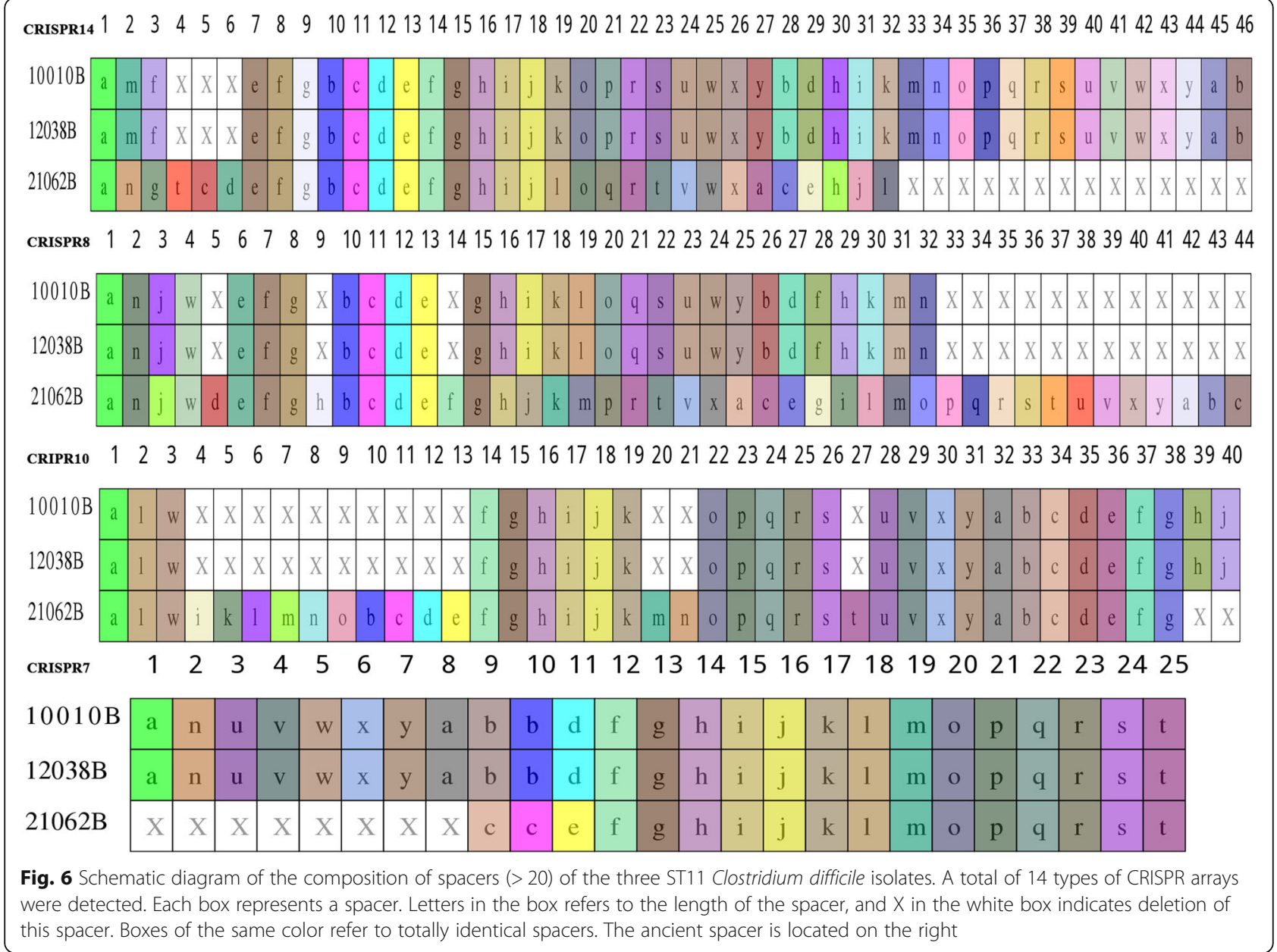

\section{Methods}

\section{Ethics statement}

This study was approved by the Ethics Committee of the National Institute for Communicable Disease Control and Prevention, China CDC. All adult subjects provided informed consent, and no child was involved. The informed consent was given orally because feces collection and further test were standard protocols for patients with diarrhea. And the consent was recorded in daily progress notes by the attending physician at the hospital.

\section{Isolates and preparation of genomic DNA}

Three ST11 C. difficile isolates with distinct RTs were isolated from elderly hospitalized patients. Details of these isolates are summarized in Table 1 and our previous study [9]. PCR-ribotyping was performed by capillary electrophoresis using both QIAXcel and ABI 3730 systems [34, 35]. Strains 630 (AM180355) and M120 (FN665653.1) were used as references throughout the investigation. All three isolates were cultured on brain heart infusion (BHI) agar plates (Oxoid, UK) supplemented with $5 \%$ sheep blood (BaoTe, China) in an anaerobic chamber $(80 \%$ nitrogen, $10 \%$ hydrogen and $10 \%$ carbon dioxide) (Mart, NL) at $37^{\circ} \mathrm{C}$ for $48 \mathrm{~h}$. Typical colonies were picked up and re-cultured on $\mathrm{BHI}$ for $24 \mathrm{~h}$ before preparation of genomic DNA using the Wizard ${ }^{\bullet}$ Genomic DNA Purification Kit (Promega, USA) according to the manufacturer's instructions.

\section{Genome sequencing and assembly}

The complete genomes of three ST11 C. difficile isolates were sequenced on the PacBio RS II platform and Illumina HiSeq 4000 platform at the Beijing Genomics Institute (BGI, Shenzhen, China). Four SMRT cells ZeroMode Wave guide arrays of sequencing, were used by the PacBio platform to generate the sub-reads set, in which PacBio subreads with length $<1 \mathrm{~kb}$ were removed. The program Pbdagcon program (https://github.com/PacificBiosciences/pbdagcon) was used for self-correction. Draft genomic contigs, which are uncontested groups of fragments, were assembled using the Celera Assembler against a high quality corrected circular consensus sequence subreads set. To improve the accuracy of the genome sequences, the GATK (https://www.broadinstitute.org/gatk/) 


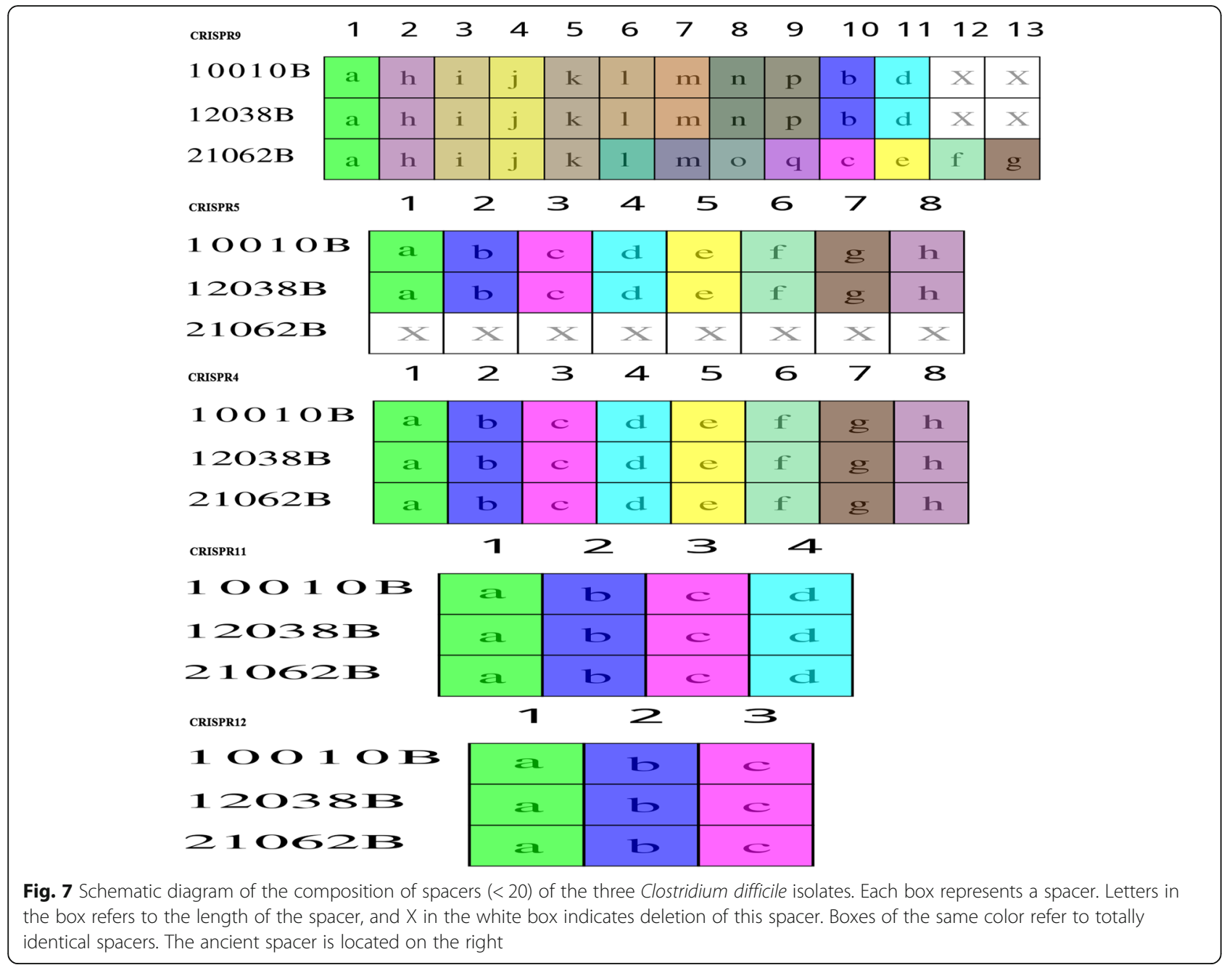

and SOAP tool packages (SOAP2, SOAPsnp, SOAPindel) were used to make single-base corrections. To trace the presence of any plasmid, the filtered Illumina reads were mapped using SOAP to the bacterial plasmid database (http://www.ebi.ac.uk/genomes/plasmid.html, last accessed July 8, 2016) using SOAP.

\section{Genome component prediction}

Gene prediction was performed on the three genomes assembled by glimmer3 (http://www.cbcb.umd.edu/software/ glimmer/) with a Hidden Markov models. tRNA, rRNA and sRNAs were recognized by using the tRNAscan-SE [36], RNAmmer, and the Rfam database, respectively [37]. The TR annotation was performed using the Tandem Repeats Finder (http://tandem.bu.edu/trf/trf.html). The minisatellite DNA and microsatellite DNAs were selected based on the number and length of the repeat units. Prophage regions were predicted using the PHAge Search Tool (PHAST) web server (http://phast.wishartlab.com/) and CRISPR identification were conducted by using the CRISPRFinder [38].
Gene annotation and protein classification

The best hit analyzed using BLAST alignment tool for function annotation. The following databases used for general function annotation: KEGG (Kyoto Encyclopedia of Genes and Genomes) [39], COG (Clusters of Orthologous Groups) [40], NR (Non-Redundant Protein Database databases) [41], Swiss-Prot [42], and GO (Gene Ontology) [43], TrEMBL, and EggNOG [44], are used for general function annotation. Four databases were used for pathogenicity and drug-resistance analysis. Virulence factors and resistance genes were identified based on the core dataset in Virulence Factors of Pathogenic Bacteria (VFDB), Antibiotic Resistance Genes Database (ARDB) https://ardb.cbcb.umd.edu/, and Comprehensive Antibiotic Resistance Database (CARD) https://card.mcmaster.ca/. The Pathogen Host Interactions (PHI) and Carbohydrate-Active enzymes (CAZy) databases [45] were also used here.

\section{Sequence analysis of the PaLoc and CdtLoc regions}

The PaLoc and CdtLoc regions were confirmed by comparison to reference CD630 genome. Orthologous gene 


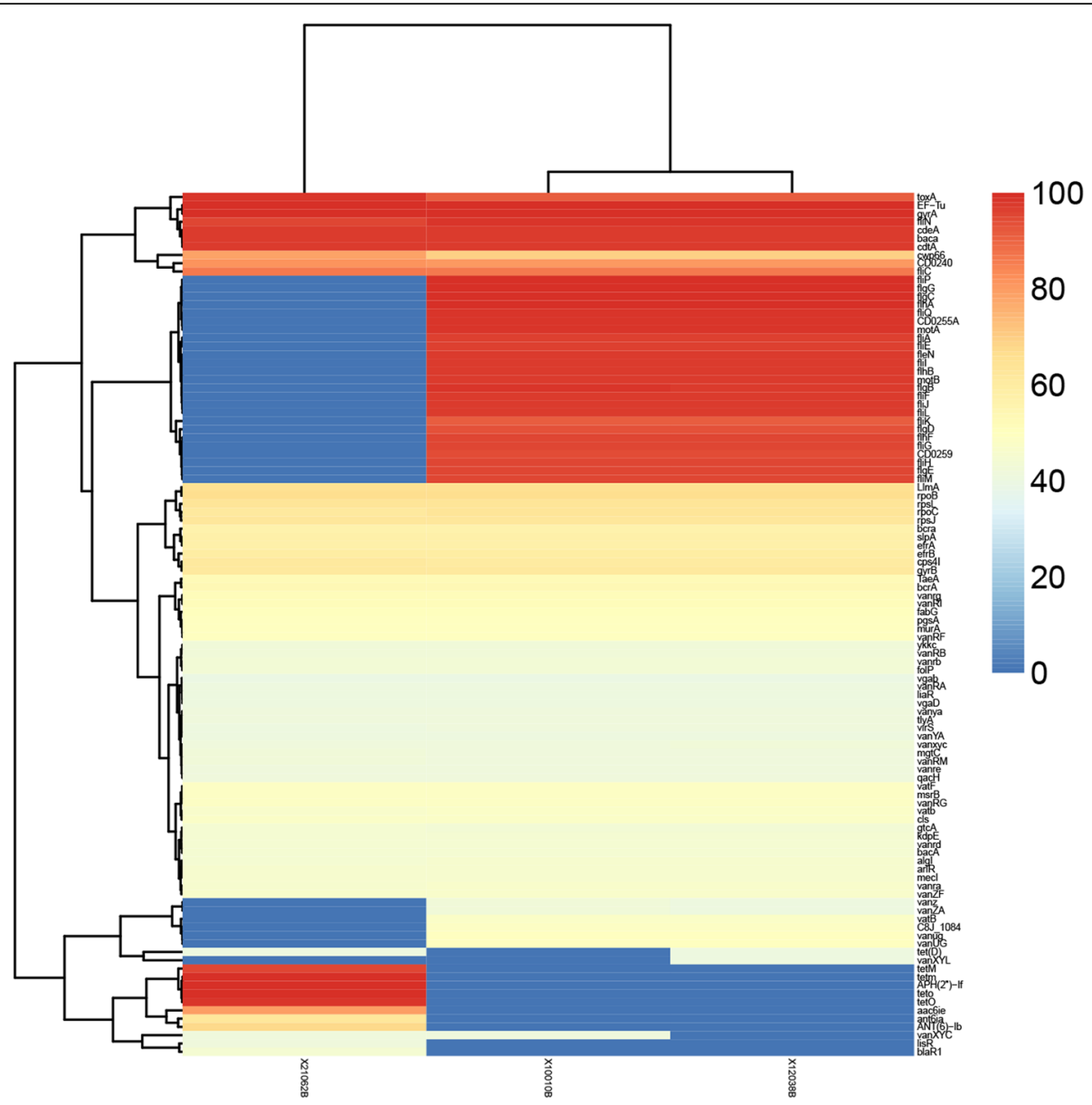

Fig. 8 Predicted antibiotic-resistance genes of the three Clostridium difficile isolates and virulence-related genes according to the CARD, ARDB and VFDB databases, respectively. The vertical line indicates the predicted genes, and the horizontal lines indicate the three isolates. Increasing numbers of gene copies are represented by the change from blue to red

(> 80\% coverage and $90 \%$ nucleotide identity) were detected in BLAST (version 2.2.12) searches. The genetic structure as well as insertions and deletions (indel) were also studied.

\section{Analysis of MGEs}

Transposons (Tns) and conjugative transposons (CTns) were identified in BLAST, searches of the $C$. difficile genome sequences or transposons sequences available at NCBI (https://www.ncbi.nlm.nih.gov/). The Tns and CTns were defined as $>80 \%$ nucleotide identity and coverage. Prophages were identified using the PHASTER web server (http://phaster.ca/). Intact and incomplete prophages sequences were defined as $\geq 80 \%$ coverage and $\geq 90 \%$ highest nucleotide identity with similar regions in bacterial genomes in the databases. To identify plasmids, reads were assembled into contigs using the SOAP denovo. Contigs were screened for plasmids using Microbial Genome BLAST against the NCBI complete plasmid database (ftp://ftp.ncbi.nlm.nih.gov/genomes/refseq/plasmid/). The potential plasmids were defined as $\geq 70 \%$ coverage and $\geq$ $80 \%$ identity. The CRISPRFinder was used for the CRISPR identification. Conserved spacers were used as anchoring points to compare CRISPR arrays across whole genomes. For each array, the repeat sequences were removed, and the list of spacers was oriented with the ancestral spacer on the right-hand side.

\section{Antimicrobial susceptibility tests}

C. difficile isolates were tested for susceptibility to moxifloxacin (MXF), vancomycin (VAN), clindamycin (CLI), tetracycline (TET), erythromycin (ERY), rifampin (RFX), levofloxacin (LFX), chloramphenicol (CHL), metronidazole (MTZ), ciprofloxacin (CIP), and meropenem using E-test strips (Biomerieux, France, and Liofilchem, Italy). The interpretation of minimum inhibitory concentration (MIC) for MTZ, MXF, CLI, CIP, LFX, and TET were interpreted according to recommendations of the Clinical and Laboratory Standards Institute (CLSI) M11-A7 and M100-S24 [46, 47], and the European Committee 
on Antimicrobial Susceptibility Testing (EUCAST) (http://www.eucst.org). The breakpoints for VAN, RFX, ERY, CHL, and meropenem were determined according to a previous study [48]. Multidrug resistance (MDR) was defined as resistance to at least three antimicrobial classes. C. difficile ATCC 700057 was included as a control in each experiment.

Antimicrobial resistance genes were predicted through comparison with the Antibiotic Resistance Genes Database (ARDB) https://ardb.cbcb.umd.edu/ [49], and Comprehensive Antibiotic Resistance Database (CARD) https:// card.mcmaster.ca/ databases [50]. Heatmap analysis was performed using the pheatmap package and stats packages in $\mathrm{R}$ software (version 2.15.3).

\section{Nucleotide sequence accession numbers}

The complete whole-genome sequences of 3 ST11 C. difficile isolates have been submitted to DDBJ/EMBL/ GenBank under the BioProject number PRJNA497978.

\section{Supplementary information}

Supplementary information accompanies this paper at https://doi.org/10. 1186/s12864-019-6184-1.

Additional file 1. Table summarizing transposals identified in the three C. difficile isolates.

\section{Abbreviations}

CDs: Coding sequences; CRISPR: Clustered regularly interspersed short palindromic repeat; HLGR: High level gentamicin resistance; MGEs: Mobile genetic elements; MLST: Multi locus sequencing typing; ncRNAs: non-coding RNAs; ORF: Open reading frame; RTs: Ribotypes; SNPs: Single nucleotide polymorphisms; TRs: Tandem repeats; WGS: Whole genome sequencing

\section{Acknowledgements}

We would like to thank the native English speaking scientists of Elixigen Company (Huntington Beach, California) for editing our manuscript.

\section{Authors' contributions}

YW, LY, WGL, WZZ, and ZJL performed the experiments. YW and LY analyzed data and finished figures. YW wrote the manuscript. YW and JXL designed the study and reviewed the manuscript. All authors read and approved the final manuscript.

\section{Funding}

This work was supported by the National Sci-Tech Key Project (grant No. 2018ZX10714-002 and 2018ZX10733402). The funders had no role in study design, data collection and analysis, decision to publish, or preparation of the article.

\section{Availability of data and materials}

The data generated and/or analyzed during the current study are available from the corresponding author on reasonable request.

\section{Ethics approval and consent to participate}

Ethics approval do not apply to our study, all institutes involved in this research are consent to participate.

\section{Consent for publication}

Every participant know and agree the publication of this manuscript.

\section{Competing interests}

The authors declare that they have no competing interests.

\section{Author details}

${ }^{1}$ State Key Laboratory of Infectious Disease Prevention and Control, National Institute for Communicable Disease Control and Prevention, Chinese Center for Disease Control and Prevention, Beijing, China. ${ }^{2}$ Collaborative Innovation Center for Diagnosis and Treatment of Infectious Diseases, Hangzhou, China. ${ }^{3} \mathrm{BGl}$-Shen zhen, main building, Beishan industry zone, Yan tian District, Shenzhen, China.

Received: 18 January 2019 Accepted: 15 October 2019

Published online: 30 October 2019

\section{References}

1. He M, Miyajima F, Roberts P, Ellison L, Pickard DJ, Martin MJ, Connor TR, Harris SR, Fairley D, Bamford KB, et al. Emergence and global spread of epidemic healthcare-associated Clostridium difficile. Nat Genet. 2013; 45(1):109-13.

2. Eyre DW, Cule ML, Wilson DJ, Griffiths D, Vaughan A, O'Connor L, Ip CLC, Golubchik T, Batty EM, Finney JM, et al. Diverse sources of C. difficile infection identified on whole-genome sequencing. N Engl J Med. 2013; 369(13):1195-205.

3. Knight DR, Thean S, Putsathit P, Fenwick S, Riley TV. Cross-sectional study reveals high prevalence of Clostridium difficile non-PCR ribotype 078 strains in Australian veal calves at slaughter. Appl Environ Microbiol. 2013:79(8):2630-5.

4. Knight DR, Elliott B, Chang BJ, Perkins TT, Riley TV. Diversity and evolution in the genome of Clostridium difficile. Clin Microbiol Rev. 2015;28(3):721-41.

5. Kuijper EJ, Barbut F, Brazier JS, Kleinkauf N, Eckmanns T, Lambert ML, Drudy D, Fitzpatrick F, Wiuff C, Brown DJ, et al. Update of Clostridium difficile infection due to PCR ribotype 027 in Europe, 2008. Euro Surveill. 2008:13(31).

6. Dingle KE, Elliott B, Robinson E, Griffiths D, Eyre DW, Stoesser N, Vaughan A, Golubchik T, Fawley WN, Wilcox MH, et al. Evolutionary history of the Clostridium difficile pathogenicity locus. Genome Biol Evol. 2014;6(1):36-52.

7. Goorhuis A, Bakker D, Corver J, Debast SB, Harmanus C, Notermans DW, Bergwerff AA, Dekker FW, Kuijper EJ. Emergence of Clostridium difficile infection due to a new hypervirulent strain, polymerase chain reaction ribotype 078. Clinical Infect Dis. 2008:47(9):1162-70.

8. Janezic S, Rupnik M. Genomic diversity of Clostridium difficile strains. Res Microbiol. 2015;166(4):353-60.

9. Suo J, Yan Z, Wu Y, Li WG, Zhang WZ, Liu XS, Liu Y, Lu J. Clostridium difficile RT 078/ST11: a threat to community population and pigs identified in elder hospitalized patients in Beijing, China. Infect Control Hosp Epidemiol. 2017; 38(11):1383-5.

10. Sebaihia M, Wren BW, Mullany P, Fairweather NF, Minton N, Stabler R, Thomson NR, Roberts AP, Cerdeno-Tarraga AM, Wang H, et al. The multidrug-resistant human pathogen Clostridium difficile has a highly mobile, mosaic genome. Nat Genet. 2006;38(7):779-86.

11. Didelot X, Eyre DW, Cule M, Ip CL, Ansari MA, Griffiths D, Vaughan A, O'Connor L, Golubchik T, Batty EM, et al. Microevolutionary analysis of Clostridium difficile genomes to investigate transmission. Genome Biol. 2012;13(12):R118.

12. Mullany P, Allan E, Roberts AP. Mobile genetic elements in Clostridium difficile and their role in genome function. Res Microbiol. 2015;166(4):361-7.

13. Brouwer MS, Warburton PJ, Roberts AP, Mullany P, Allan E. Genetic organisation, mobility and predicted functions of genes on integrated, mobile genetic elements in sequenced strains of Clostridium difficile. PLoS One. 2011;6(8):e23014.

14. Monot M, Boursaux-Eude C, Thibonnier M, Vallenet D, Moszer I, Medigue C, Martin-Verstraete I, Dupuy B. Reannotation of the genome sequence of Clostridium difficile strain 630. J Med Microbiol. 2011;60(Pt 8):1193-9.

15. Jin H, Ni K, Wei L, Shen L, Xu H, Kong Q, Ni X. Identification of Clostridium difficile RT078 from patients and environmental surfaces in Zhejiang Province, China. Infect Control Hosp Epidemiol. 2016;37(6):745-6.

16. Monot M, Eckert C, Lemire A, Hamiot A, Dubois T, Tessier C, Dumoulard B, Hamel B, Petit A, Lalande V, et al. Clostridium difficile: new insights into the evolution of the pathogenicity locus. Sci Rep. 2015;5:15023.

17. Stabler RA, He M, Dawson L, Martin M, Valiente E, Corton C, Lawley TD, Sebaihia M, Quail MA, Rose G, et al. Comparative genome and phenotypic analysis of Clostridium difficile 027 strains provides insight into the evolution of a hypervirulent bacterium. Genome Biol. 2009;10(9):R102. 
18. Brouwer MS, Roberts AP, Mullany P, Allan E. In silico analysis of sequenced strains of Clostridium difficile reveals a related set of conjugative transposons carrying a variety of accessory genes. Mob Genet Elem. 2012; 2(1):8-12.

19. Roberts AP, Mullany P. Tn916-like genetic elements: a diverse group of modular mobile elements conferring antibiotic resistance. FEMS Microbiol Rev. 2011;35(5):856-71.

20. Jasni AS, Mullany P, Hussain H, Roberts AP. Demonstration of conjugative transposon (Tn5397)-mediated horizontal gene transfer between Clostridium difficile and enterococcus faecalis. Antimicrob Agents Chemother. 2010;54(11):4924-6.

21. Amy J, Johanesen P, Lyras D. Extrachromosomal and integrated genetic elements in Clostridium difficile. Plasmid. 2015;80:97-110.

22. Dong D, Chen X, Jiang C, Zhang L, Cai G, Han L, Wang X, Mao E, Peng $Y$. Genetic analysis of Tn916-like elements conferring tetracycline resistance in clinical isolates of Clostridium difficile. Int J Antimicrob Agents. 2014;43(1):73-7.

23. Roberts AP, Allan E, Mullany P. The impact of horizontal gene transfer on the biology of Clostridium difficile. Adv Microb Physiol. 2014;65:63-82.

24. Lyras D, Rood JI. Transposition of Tn4451 and Tn4453 involves a circular intermediate that forms a promoter for the large resolvase, TnpX. Mol Microbiol. 2000;38(3):588-601.

25. Hallgren A, Saeedi B, Nilsson M, Monstein HJ, Isaksson B, Hanberger $H_{\text {, }}$ Nilsson LE. Genetic relatedness among enterococcus faecalis with transposon-mediated high-level gentamicin resistance in Swedish intensive care units. J Antimicrob Chemother. 2003;52(2):162-7.

26. Boudry P, Semenova E, Monot M, Datsenko KA, Lopatina A, Sekulovic O, Ospina-Bedoya M, Fortier LC, Severinov K, Dupuy B, et al. Function of the CRISPR-Cas System of the Human Pathogen Clostridium difficile. mBio. 2015; 6(5):e01112-5.

27. Stern A, Mick E, Tirosh I, Sagy O, Sorek R. CRISPR targeting reveals a reservoir of common phages associated with the human gut microbiome. Genome Res. 2012;22(10):1985-94

28. Makarova KS, Haft DH, Barrangou R, Brouns SJ, Charpentier E, Horvath P, Moineau S, Mojica FJ, Wolf Yl, Yakunin AF, et al. Evolution and classification of the CRISPR-Cas systems. Nat Rev Microbiol. 2011;9(6):467-77.

29. Andersen JM, Shoup M, Robinson C, Britton R, Olsen KE, Barrangou R. CRISPR diversity and microevolution in Clostridium difficile. Genome Biol Evol. 2016;8(9):2841-55

30. Wang S, Hong W, Dong S, Zhang ZT, Zhang J, Wang L, Wang Y. Genome engineering of Clostridium difficile using the CRISPR-Cas9 system. Clin Microbiol Infect. 2018;24(10):1095-9.

31. Corver J, Bakker D, Brouwer MS, Harmanus C, Hensgens MP, Roberts AP, Lipman LJ, Kuijper EJ, van Leeuwen HC. Analysis of a Clostridium difficile PCR ribotype 078100 kilobase island reveals the presence of a novel transposon, Tn6164. BMC Microbiol. 2012;12:130

32. Tsvetkova K, Marvaud JC, Lambert T. Analysis of the mobilization functions of the vancomycin resistance transposon Tn1549, a member of a new family of conjugative elements. J Bacteriol. 2010;192(3):702-13.

33. Knight DR, Androga GO, Ballard SA, Howden BP, Riley TV. A Phenotypically Silent vanB2 Operon Carried on a Tn1549-Like Element in Clostridium difficile. mSphere. 2016;1(4).

34. Liao F, Li W, Gu W, Zhang W, Liu X, Fu X, Xu W, Wu Y, Lu J. A retrospective study of community-acquired Clostridium difficile infection in Southwest China. Sci Rep. 2018:8(1):3992.

35. Knetsch CW, Lawley TD, Hensgens MP, Corver J, Wilcox MW, Kuijper EJ. Current application and future perspectives of molecular typing methods to study Clostridium difficile infections. Euro Surveill. 2013;18(4):20381.

36. Lowe TM, Eddy SR. tRNAscan-SE: a program for improved detection of transfer RNA genes in genomic sequence. Nucleic Acids Res. 1997;25(5): 955-64.

37. Lagesen K, Hallin P, Rodland EA, Staerfeldt HH, Rognes T, Ussery DW. RNAmmer: consistent and rapid annotation of ribosomal RNA genes. Nucleic Acids Res. 2007:35(9):3100-8.

38. Grissa I, Vergnaud G, Pourcel C. CRISPRFinder: a web tool to identify clustered regularly interspaced short palindromic repeats. Nucleic Acids Res. 2007;35(Web Server issue):W52-7

39. Kanehisa M, Goto S, Hattori M, Aoki-Kinoshita KF, Itoh M, Kawashima S, Katayama T, Araki M, Hirakawa M. From genomics to chemical genomics: new developments in KEGG. Nucleic Acids Res. 2006:34(Database issue): D354-7.
40. Tatusov RL, Fedorova ND, Jackson JD, Jacobs AR, Kiryutin B, Koonin EV, Krylov DM, Mazumder R, Mekhedov SL, Nikolskaya AN, et al. The COG database: an updated version includes eukaryotes. BMC Bioinformatics. 2003:4:41

41. Li W, Jaroszewski L, Godzik A. Tolerating some redundancy significantly speeds up clustering of large protein databases. Bioinformatics (Oxford, England). 2002;18(1):77-82

42. Bairoch A, Apweiler R. The SWISS-PROT protein sequence database and its supplement TrEMBL in 2000. Nucleic Acids Res. 2000;28(1):45-8.

43. Ashburner M, Ball CA, Blake JA, Botstein D, Butler H, Cherry JM, Davis AP, Dolinski K, Dwight SS, Eppig JT, et al. Gene ontology: tool for the unification of biology. The Gene Ontology Consortium. Nature Genetics. 2000:25(1):25-9.

44. Huerta-Cepas J, Szklarczyk D, Forslund K, Cook H, Heller D, Walter MC, Rattei T, Mende DR, Sunagawa S, Kuhn M, et al. eggNOG 4.5: a hierarchical orthology framework with improved functional annotations for eukaryotic, prokaryotic and viral sequences. Nucleic Acids Res. 2016:44(D1):D286-93.

45. Urban M, Cuzick A, Rutherford K, Irvine A, Pedro H, Pant R, Sadanadan V, Khamari L, Billal S, Mohanty S, et al. PHI-base: a new interface and further additions for the multi-species pathogen-host interactions database. Nucleic Acids Res. 2017;45(D1):D604-d610.

46. CLSI. Methods of antimicrobial susceptibility testing of anaerobic Bacteria approved standard M11-A8. 8th ed. Wayne: Clinical and Laboratory Standards Institute; 2012

47. CLSI. Performance standards for antimicrobial susceptibility testing twentyfourth informational supplement CLSI M 100-S28. Wayne: Clinical and Lavoratory Standards Instiute; 2018.

48. Magiorakos AP, Srinivasan A, Carey RB, Carmeli Y, Falagas ME, Giske CG, Harbarth S, Hindler JF, Kahlmeter G, Olsson-Liljequist B, et al. Multidrugresistant, extensively drug-resistant and pandrug-resistant bacteria: an international expert proposal for interim standard definitions for acquired resistance. Clin Microbiol Infect. 2012;18(3):268-81.

49. Liu B, Pop M. ARDB--antibiotic resistance genes database. Nucleic Acids Res. 2009;37(Database issue):D443-7.

50. McArthur AG, Waglechner N, Nizam F, Yan A, Azad MA, Baylay AJ, Bhullar K Canova MJ, De Pascale G, Ejim L, et al. The comprehensive antibiotic resistance database. Antimicrob Agents Chemother. 2013;57(7):3348-57.

\section{Publisher's Note}

Springer Nature remains neutral with regard to jurisdictional claims in published maps and institutional affiliations.

Ready to submit your research? Choose BMC and benefit from:

- fast, convenient online submission

- thorough peer review by experienced researchers in your field

- rapid publication on acceptance

- support for research data, including large and complex data types

- gold Open Access which fosters wider collaboration and increased citations

- maximum visibility for your research: over $100 \mathrm{M}$ website views per year

At $\mathrm{BMC}$, research is always in progress.

Learn more biomedcentral.com/submissions 